\title{
COMMENTARY
}

\section{Statins in pneumonia - magic versus science?}

\author{
Peter S Kruger ${ }^{1,2, *}$ and Robert M Thomas' \\ See related research by Nielsen et al., http://ccforum.com/content/16/4/R122
}

\begin{abstract}
Several studies have investigated the use of statins as an adjunct in the treatment of pneumonia, some with conflicting conclusions. The most recent of these large observational studies again suggests statin use is associated with an improved outcome for patients with pneumonia. How best to incorporate these findings into current practice is of great interest. Hidden confounders plague database interrogation and so cast doubt on the real or causal nature of observed associations. Data from large, observational studies must be complemented by smaller biological studies and randomised controlled trials in an effort to complete missing pieces in the biological puzzle of the use of statins in patients with pneumonia.
\end{abstract}

\section{Introduction}

The latest study on the therapeutic value of statins in pneumonia adds further support to the association between statin use and improved patient outcomes [1]. The role of statins in the management of sepsis has been increasingly studied but remains contentious. Animal studies of statin use in sepsis have shown a significant benefit with respect to mortality [2] but a plethora of observational studies have come to conflicting conclusions [3,4]. Many mechanisms have been postulated to explain why statins may influence sepsis [5], and it is possible some of these may be of particular benefit in pneumonia [6-8].

Statins are taken by millions of people around the world and pneumonia represents one of the most common infections seen in clinical practice. This provides an opportunity to review a large number of cases of pneumonia that involve coincidental statin use. As would be expected for a drug targeting vascular disease and

${ }^{*}$ Correspondence: peter_kruger@health.qld.gov.au

'Princess Alexandra Hospital, I pswich Road, Wooloongabba, Brisbane, 4102

Australia

Full list of author information is available at the end of the article hypercholesterolaemia, statin users have different comorbidities and risk profiles to those patients that do not take statins. Therefore, observational and retrospective studies are potentially confounded by both an unhealthy user effect (a cohort often older with more coexisting cardiovascular disease) and the 'healthy user' effect [9].

\section{Current studies}

The recent study by Nielsen and colleagues [1] is a well conducted, large, observational study. The authors provide extensive detail on coexisting diseases in each of the cohorts in an effort to reveal hidden confounders that plague database interrogation. This paper adds another observational study to a large bank that already exists addressing the outcome from pneumonia in statin users [10-13]. It serves to remind us that while again suggesting a possible therapeutic role for these agents in pneumonia, it does not prove a clear cause and effect relationship.

The utility of the study is weakened by a number of factors. Firstly, it defined 'current use' as one prescription filled in the past 125 days. While the results suggest the improvement in pneumonia outcome was associated with current and not former statin users, a huge variation in timing of statin administration in relation to onset of infection is possible within these definitions. In addition to the timing of administration, the impact of one statin over another or drug dosage remains unclear. Finally, large registry databases pose other challenges. As was highlighted recently, both the consistent use of a diagnostic category over time and the motivations for recording specific diagnosis can further confound the validity of results from large national or administrative databases [14].

It is fortuitous that prevalence has provided the opportunity to observe statin use in pneumonia patients. These observations have provided the impetus to investigate statins as a potential adjuvant therapy for severe lung injury. Two randomised controlled trials are currently underway: Statins for Acutely Injured Lungs from Sepsis (SAILS) and Hydroxymethylglutaryl-CoA reductase inhibition with simvastatin in Acute lung injury to Reduce Pulmonary dysfunction (HARP 2).

SAILS will compare $20 \mathrm{mg}$ rosuvastatin to placebo. In contrast, HARP-2 will compare $80 \mathrm{mg}$ simvastatin to 
placebo. Whilst these may be equipotent doses in the management of hypercholesterolaemia, it remains unknown what effects these agents at these doses will have in acute lung injury. These two drugs have pharmacokinetic differences, including lipid solubility, volume of distribution, metabolism and potency. Without an explanation of how statins may benefit patients with lung injury, predicting the impact of differing pharmacology is impossible. Compared to the general population, the pharmacokinetics of atorvastatin differs in critical illness, and perhaps with sepsis in particular [15]. Exploring commonly used statin pharmacology in critically ill patients with pneumonia would better define doseresponse relationships on varied biological endpoints and this may provide some valuable insights into mechanisms that could explain an association with improved patient outcomes.

In addition to statin use possibly being associated with a reduction in the severity of infection, a second intriguing possibility is that statins may reduce the risk of infection. A post hoc analysis of the JUPITER trial suggested a modest reduction in the incidence of pneumonia in patients randomised to receive $20 \mathrm{mg}$ of rosuvastatin [16]. A nested case control study has also suggested a reduced incidence of pneumonia in statin users [17]. The recent study by Nielsen and colleagues [1] again suggests a decrease in the risk of hospitalization for pneumonia with statin use, but only after adjustment for potential confounding variables. Pneumonia represents an illness with known risk factors and the administration of statins as preventative therapy could be prospectively explored in this patient population in an effort to avoid confusion from uncontrolled or unknown factors.

\section{Conclusion}

Rather than question what can be learned from observational data while the results of randomised trials are awaited, perhaps we can use all these research methods to better inform our clinical practice. Whilst observational studies to date are far from conclusive, it is hard to see how randomised controlled trials will resolve a complex debate that is still in its infancy. It is more likely that a multipronged approach with retrospective large databases, smaller biological studies and randomised trials will help complete the biological puzzle of statin use and its role in patients with pneumonia.

\section{Abbreviations}

HARP 2, Hydroxymethylglutaryl-CoA reductase inhibition with simvastatin in Acute lung injury to Reduce Pulmonary dysfunction; SAILS, Statins for Acutely Injured Lungs from Sepsis.

\section{Competing interests}

The authors declare that they have no competing interests.

\section{Author details}

'Princess Alexandra Hospital, Ipswich Road, Wooloongabba, Brisbane, 4102 Australia. ${ }^{2}$ University of Queensland, Brisbane, 4102 Australia.

Published: 21 September 2012

\section{References}

1. Nielsen AG, Nielsen RB, Riis AH, Johnsen SP, Sorensen HT, Thomsen RW: The impact of statin use on pneumonia risk and outcome: a combined population-based case-control and cohort study. Crit Care 2012, 16:R122.

2. Merx MW, Weber C: Statins in the intensive care unit. Curr Opin Crit Care 2006, 12:309-314.

3. Janda S, Young A, Fitzgerald JM, Etminan M, Swiston J: The effect of statins on mortality from severe infections and sepsis: a systematic review and meta-analysis. J Crit Care 2010, 25:656.e7-22.

4. Falagas ME, Makris GC, Matthaiou DK, Rafailidis PI: Statins for infection and sepsis: a systematic review of the clinical evidence. J Antimicrob Chemother 2008, 61:774-785.

5. Kruger PS: Statins: the next anti-endotoxin. Crit Care Resusc 2006, 8:223-226.

6. Fedson DS: Confronting the next influenza pandemic with antiinflammatory and immunomodulatory agents: why they are needed and how they might work. Influenza Other Respi Viruses 2009, 3:129-142.

7. Boyd AR, Hinojosa C, Rodriguez PJ, Orihuela CJ: Impact of oral simvastatin therapy on acute lung injury in mice during pneumococcal pneumonia. BMC Microbiol 2012, 12:73.

8. Grommes J, Vijayan S, Drechsler M, Hartwig H, Mörgelin M, Dembinski R, Jacobs M, Koeppel TA, Binnebösel M, Weber C, Soehnlein O: Simvastatin reduces endotoxin-induced acute lung injury by decreasing neutrophil recruitment and radical formation. PLoS One 2012, 7:e38917.

9. Patrick AR, Shrank WH, Glynn RJ, Solomon DH, Dormuth CR, Avorn J, Cadarette SM, Mogun H, Brookhart MA: The association between statin use and outcomes potentially attributable to an unhealthy lifestyle in older adults. Value Health 2011, 14:513-520.

10. Rothberg MB, Bigelow C, Pekow PS, Lindenauer PK: Association between statins given in hospital and mortality in pneumonia patients. J Gen Intern Med 2012, 27:280-286.

11. Yende S, Milbrandt EB, Kellum JA, Kong L, Delude RL, Weissfeld LA, Angus DC Understanding the potential role of statins in pneumonia and sepsis. Crit Care Med 2011, 39:1871-1878.

12. Vandermeer ML, Thomas AR, Kamimoto L, Reingold A, Gershman K, Meek J, Farley MM, Ryan P, Lynfield R, Baumbach J, Schaffner W, Bennett N, Zansky S: Association between use of statins and mortality among patients hospitalized with laboratory-confirmed influenza virus infections: a multistate study. J Infect Dis 2012, 205:13-19.

13. Chalmers JD, Short PM, Mandal P, Akram AR, Hill AT: Statins in community acquired pneumonia: Evidence from experimental and clinical studies. Respir Med 2010, 104:1081-1091.

14. Sarrazin MS, Rosenthal GE: Finding pure and simple truths with administrative data. JAMA 2012, 307:1433-1435.

15. Kruger PS, Freir NM, Venkatesh B, Robertson TA, Roberts MS, Jones M: A preliminary study of atorvastatin plasma concentrations in critically ill patients with sepsis. Intensive Care Med 2009, 35:717-721.

16. Novack V, MacFadyen J, Malhotra A, Almog Y, Glynn RJ, Ridker PM: The effect of rosuvastatin on incident pneumonia: results from the JUPITER trial. CMAJ 2012, 184:E367-372

17. Schlienger RG, Fedson DS, Jick SS, Jick H, Meier CR: Statins and the risk of pneumonia: a population-based, nested case-control study. Pharmacotherapy 2007, 27:325-332.

doi:10.1186/cc11479

Cite this article as: Kruger PS, Thomas RM: Statins in pneumonia - magic versus science? Critical Care 2012, 16:157. 